\title{
Contrastes morfológicos entre los nombres locativos del chino mandarín y el español
}

DOI: $\underline{\text { https://doi.org/10.33262/ap.v3i1.40 }}$

\begin{abstract}
(c) (1) (2)(2)
Morphological contrasts between the locative names of chinese mandarin and Spanish
\end{abstract}

Diana Llanes Rosales ${ }^{1}$

\begin{abstract}
.
The examination of the different lexical formation of locative nouns in Chinese and Spanish schemes permits us to observe the relation between those most systematic and productive mechanisms of both languages. Thus, it is verified the equivalence between the nominal nucleus of the Spanish phrasal composition and the Chinese locative components. However, the Spanish's locative nouns seem not to present the similarity to the grammaticalization progress that some Chinese locative components have experienced, on the other hand, it is pointed out that while some Chinese locative components achieve certain lexical autonomy in particular context; other components correspond functionally to the Spanish suffixes elements.
\end{abstract}

Keywords: Contrastive Linguistics, Morphology, Chinese, Spanish, Locative nouns.

\section{Resumen.}

El examen de los nombres con sentido locativo del español y del chino se prestan a un análisis contrastivo, que entre otros aspectos pone de manifiesto la complejidad y riqueza de los procesos morfológicos que intervienen en la formación léxica, y permiten observar las relaciones que se establecen entre los mecanismos más sistemáticos y productivos de ambos

${ }^{1}$ Universidad de La Habana, Facultad de Turismo. La Habana, Cuba. ybencomo@ftur.uh.cu 
códigos. Se comprueba la equivalencia entre los núcleos nominales de la composición sintagmática del español con los formantes locativos del chino. Aunque, en español no parece darse un caso claro de gramaticalización semejante al que ha experimentado algún formante locativo del chino y, por otra parte, se argumenta que mientras algunos formantes del chino alcanzan cierta autonomía léxica en determinados contextos, otros se corresponden funcionalmente con los elementos sufijales del español.

Palabras claves: Lingüística contrastiva, Morfología, Chino, Español, Nombres locativos.

\section{Introducción.}

La morfología es la rama de la lingüística que estudia la forma de las palabras. Es precisamente mediante su estudio que las diferencias entre las lenguas se hacen evidentes. Existen tres clasificaciones según la morfología de la lengua, las aislantes, las aglutinantes y las flexivas. Las lenguas aislantes usan morfemas gramaticales que son palabras separadas, las aglutinantes como se pudiera inferir, usan morfemas gramaticales en forma de sílabas adjuntadas llamadas afijos, y por último, las lenguas flexivas, van un paso más allá y cambian los fonemas para expresar morfemas gramáticos.

El Chino Mandarín se clasifica como una lengua aislante y el español por su parte se considera una lengua flexiva. Pudiera deducirse entonces, que ambas lenguas por sus tipologías, son totalmente diferentes, pero es precisamente esta distancia la que permite establecer comparaciones y arribar a puntos de contacto no tan evidentes a simple vista.

Los nombres locativos entendidos tanto en una como en otra, presentan un componente morfológico en su formación léxica.

\section{Tipologías morfológicas de los nombres locativos en Chino Mandarín.}

En chino mandarín, los nombres locativos están constituidos por la adición de unos constituyentes pospuestos, denominados formantes locativos, que vacilan entre la derivación y la composición.

Podría decirse que en el chino clásico todas las palabras eran monosilábicas, y desde el punto de vista semántico con un sentido independiente. Con la evolución de la lengua, fue creciendo el número de palabras bisílabas y la mayoría de los morfemas se pueden combinar para formar palabras. En los nombres locativos estos componentes se denominan formantes locativos, pues conservan el sentido locativo de origen.

Existen muchos de estos formantes que comparten un significado similar, esto puede deberse a que en el chino clásico ambas palabras eran sinónimos, es por ello que en ocasiones la traducción de estas palabras al español o cualquier otra lengua se complejice. 
Como analizara el profesor Cheng Ling Liu de la Universidad de Valladolid, España, en su artículo: "Contrastive morphology of locative nouns in Mandarin Chinese and Spanish" los morfemas diàn 店, háng 行, fáng 坊 y pù 舖, son equivalentes al significado de tienda en español, aunque cada uno tiene sus propios elementos o compuestos.

A continuación, se muestra una tabla planteada por dicho investigador para analizar este fenomeno con los formantes locativos del chino mandarín.

Tabla 1: Nombres locativos en chino mandarín

\section{Formantes}

diàn 店 tienda

háng 行 tienda

féng 坊 tienda

pù 舖 tienda

jiān 間 cuarto

shì 室 cuarto

táng 堂 cuarto

\section{Nombres de lugar}

huā diàn 花店 'flor' 'tienda' $\rightarrow$ floristería

fàn diàn 飯店 'arroz' 'tienda' $\rightarrow$ hotel

wǔ jīn háng 五金行 ‘cinco' 'metal' 'tienda' $\rightarrow$ ferretería

biăo háng 鐘錶行 ‘campana' 'reloj' 'tienda' $\rightarrow$ relojería

miàn bāo féng 麵包坊 'pasta' 'envolver' 'tienda' $\rightarrow$ panadería

huā féng 花坊 'flor' 'tienda' $\rightarrow$ floristería

dàng pù 當舖 'empeñar' 'tienda' $\rightarrow$ casa de empeños

zhōng yào pù 中藥舖 'chino' 'medicina' 'tienda' $\rightarrow$ herboristería china

xǐ shǒu jiān 洗手間 'lavar' 'mano' 'cuarto' $\rightarrow$ cuarto de baño

tíng shī jiān 停屍間 ‘guardar' 'cadáver' ‘cuarto’ $\rightarrow$ morgue

shí yàn shì 實驗室 ‘experimentar’ ‘examinar’cuarto’ $\rightarrow$ laboratorio

wēn shì 溫室 ‘templado’ ‘cuarto’ $\rightarrow$ invernadero

zăo táng 澡堂 ‘baño' ‘cuarto' $\rightarrow$ casa de baño

shí táng 食堂 'comer' 'cuarto' $\rightarrow$ comedor 
ISSN: 2773-7330

guăn 館 casa bó wù guăn 博物館 'amplio' 'objeto' 'casa' $\rightarrow$ museo, pinacoteca

shè 舍 casa

tú shū guăn 圖書館 'dibujo' 'libro' 'casa' $\rightarrow$ biblioteca

cān guăn 餐館 'comida' 'casa' $\rightarrow$ restaurante

nóng shè 農舍 ‘agrícola' 'casa' $\rightarrow$ casa de campo

sù shè 宿舍 'alojarse' 'casa' $\rightarrow$ residencia

chăng 廠 fábrica， fā diàn chăng 發電廠 'producir' ‘electricidad' ‘fábrica' $\rightarrow$ central

taller

eléctrica

yìn shuā chăng 印刷廠 'imprimir' 'cepillar' 'fábrica' $\rightarrow$ imprenta

fáng 房 habitación yào fáng 藥房 ‘medicina' 'habitación' $\rightarrow$ farmacia

chú fáng 廚房 ‘cocina' 'habitación’ $\rightarrow$ cocina

chăng 場 explanada guăn chăng 廣場 'amplio' 'explanada' $\rightarrow$ plaza

tíng chē chăng 停車場 ‘aparcar' 'vehículo' ‘explanada' $\rightarrow$ aparcamien-to

zú qiú chăng 足球場 ‘pié’ 'pelota' ‘explanada' $\rightarrow$ campo de fútbol

yuàn 院 edificio gū ér yuàn 孤兒院 ‘solo' 'hijo' ‘edificio' $\rightarrow$ orfanato

ȳ̄ yuàn 醫院 'medicina' 'casa' $\rightarrow$ hospital

yuán 園 jardín huā yuán 花園 ‘flor’ ‘jardín’ $\rightarrow$ jardín

mù yuán 墓園 ‘tumba' ‘jardín’ $\rightarrow$ cementerio

tīng 廳 sala (salón) cān tīng 餐廳 'comida' 'sala' $\rightarrow$ restaurante

kè tīng 客廳 ‘huésped' ‘sala' $\rightarrow$ salón

kù 庫 almacén shuǐ kù 水庫 ‘agua' ‘almacén’ $\rightarrow$ embalse, presa

chē kù 車庫 ‘coche’ ‘almacén’ $\rightarrow$ garaje 
ISSN: 2773-7330

suǒ 所 sitio

cè suǒ 廁所 'retrete' 'sitio' $\rightarrow$ aseo

jú 局 oficina

zhěn suǒ 診所 ‘diagnosticar' 'sitio' $\rightarrow$ clínica

zhàn 站 parada

chē zhàn 車站 'vehículo' 'parada' $\rightarrow$ estación

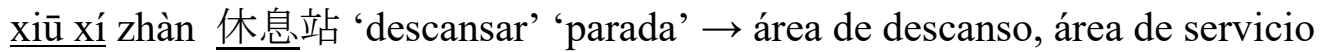

shōu fèi zhàn 收費站 'recibir' 'tasa' 'parada' $\rightarrow$ peaje

zhōng xīn 中心 jiàn kāng zhōng xīn 健康中心 ‘salud' ‘salud' ‘centro' $\rightarrow$ centro de salud

centro

gòu wùzhōng xīn 購物中心 ‘comprar' 'objeto' ‘centro' $\rightarrow$ centro comercial

yán jiù zhōng xīn 研究中心 ‘investigar' 'estudiar’'centro' $\rightarrow$ centro de inves-

shì chăng 市場 tiào zăo shì chăng 跳蛋市場 ‘saltar'”pulga' ‘mercado' $\rightarrow$ mercadillo

mercado chāo jí shì chăng 超級市場 ‘super' 'clase' ‘mercado' $\rightarrow$ supermercado

huā huì shì chăng 花卉市場 'flor' 'flor' ‘mercado' $\rightarrow$ mercado de

tái 台 plataforma yáng tái 陽台 'sol' 'plataforma' $\rightarrow$ balcón

jiăng tái 講台 'hablar' 'plataforma' $\rightarrow$ estrado

láng 廊 pasillo zǒu láng 走廊 ‘andar' 'pasillo' $\rightarrow$ pasillo

huà láng 畫廊 ‘pintura' 'pasillo' $\rightarrow$ galería de pinturas

chí 池 fuente yú yǒng chí 游泳池 'nadar' 'nadar' fuente' $\rightarrow$ piscina

wǔ chí 舞池 ‘baile' ‘fuente' $\rightarrow$ pista de baile

shuǐ chí 水池 'agua' 'fuente' $\rightarrow$ fuente

tíng 亭porche diàn huà tíng 電話亭 ‘teléfono' 'porche' $\rightarrow$ cabina telefónica

shoù piào tíng 售票亭 ‘vender' 'billete' ‘porche' $\rightarrow$ taquilla 
ISSN: 2773-7330

yín hán 銀行 banco luăn zǐ yín hán 卵子銀行 ‘óvulo' ‘sufijo' ‘banco' $\rightarrow$ banco de óvulos qīng zǐ yín hán 精子銀行 ‘esperma’ ‘sufijo’ ‘banco’ $\rightarrow$ banco de esperma

găng 港 puerto yú găng 漁港 'pesca' ‘puerto’ $\rightarrow$ puerto pesquero

jiào 窝 bodega jiǔ jiào 酒窝 'alcohol' 'bodega' $\rightarrow$ bodega

Fuente: Anuario de Lingüística Hispánica, XXV (2009)Universidad de Valladolid, Chenling LIU.

Como puede observarse, los formantes locativos presentan, en general, una estructura monosilábica que se pospone a otros morfemas léxicos o a palabras compuestas y todos ellos pueden combinarse con cualquier categoría gramatical (nombres, pero también verbos, adjetivos, adverbios e incluso sintagmas complejos).

Desde el punto de vista sintáctico, estos nombres locativos presentan estructuras fijas tanto en el orden de los componentes como en su contigüidad, de modo que no admiten la intercalación de otros elementos. Cuando se presenta la modificación, solo es posible aquella complementación que afecta al compuesto en su totalidad. Por ejemplo, los elementos que integran los siguientes compuestos son inseparables y presentan un orden fijo: yào jú 药局 ( 'medicina' 'oficina') cuya traduccion seria farmacia, si se plantea de la siguiente forma jú yào 局药 pierde este significado anterior y se transforma en dos significados individuales 'oficina' y 'medicina' respectivamente, de forma similar ocurre con el siguiente ejemplo zhōng biăo diàn 钟表店 ('campana' 'reloj' 'tienda' ) cuya traduccion se corresponde con relojería si intercalamos algun caracter de la siguiente forma zhōng he biăo háng 种和表点 pierde el significado anterior ocurriendo una separacion entre los elementos zhōng种 y el resto de los caracteres, resultando incomprensible.

\section{Tipologías morfológicas de los nombres locativos en español.}

Según el proceso morfológico, los nombres de lugar en español se pueden clasificar en varios grupos. En primer lugar, las palabras formadas por derivación mediante un sufijo de significado locativo (Almela 1999: 78, Rainer, 1993: 72-73, Santiago Lacuesta y Bustos Gisbert 1999: 4538, 4550-4560, Varela 2005: 44, 46; Amador Rodríguez, 2009: 57): frutería1, discoteca, hipódromo, rectorado, vestuario, decanato, embarcadero, mostrador2, freiduría, viñedo, cochera, abadía, aparcamiento, laboratorio, etc. Sin embargo, la mayoría de estos sufijos no se limita a la significación de 'lugar'.Amador Rodríguez (2009: 57) indica que además de la designación de agente, instrumento y acción, las terminaciones -dor, -dero, -ario y -miento también pueden producir nombres de lugar. Por otra parte, los autores suelen 
referirse a las diferencias de rentabilidad de cada sufijo, pero se señala que -ería presenta la productividad más elevada (Santiago Lacuesta y Bustos Gisbert 1999: 4550-4554). En segundo lugar, los escasos compuestos formados por verbo y nombre como guardarropa y guardamuebles. Según Val Álvaro (1999: 4794), el valor locativo del tipo verbo más nombre "se desprende de la relación que perciben los hablantes (relación de contenido a continente), entre el objeto designado por el compuesto (guardarropa) y el que se ve afectado por el verbo (ropa) y las características propias de dicho objeto. Esto propicia el sentido derivado por especialización semántica de 'armario ropero"”.

En tercer lugar, se encuentra el tipo de las aposiciones formadas por dos nombres yuxtapuestos, como bar taberna, salón comedor, casa cuna, café teatro, granja escuela, etc. En estos compuestos, el segundo sustantivo es una aposición con valor de adjetivo que atribuye una propiedad al primer sustantivo, núcleo del compuesto.

Por último, se en-cuentra un grupo de sustantivos locativos que responde a la estructura $\mathrm{N}$ de N. Este tipo resulta especialmente interesante para este analisis, pues, de una parte, alcanza una elevada productividad en español sobre todo con respecto al tipo apositivo y, por otra parte, muestra una notable semejanza con la formación de los nombres de lugar en chino mandarín, tanto en la selección de los componentes léxicos (p. ej., cuarto, casa, taller, etc.) como en el resultado de la composición (p. ej., campo de fútbol o cuarto de baño). Parece conveniente, por tanto, dedicar mayor atención a la ejemplificación y descripción de estos nombres locativos del tipo $\mathrm{N}$ de $\mathrm{N}$ en español pues son los que aportan un contraste interesante con los expuestos en chino mandarín, con lo que percibe un cierto grado de paralelismo entre ambas lenguas. Así, en la tabla siguiente se reúnen ejemplos representativos de nombres de lugar en español formados mediante la secuencia $\mathrm{N}$ de $\mathrm{N}$.

Tabla 2: Nombres de lugar de estructura $\mathrm{N}$ de $\mathrm{N}$ en español

Núcleo Ejemplos

banco banco de alimentos, banco de arena, banco de embriones, banco de esperma, banco de órganos, banco de óvulos, banco de pruebas, banco de sangre

campo de batalla, campo de baloncesto, campo de béisbol, campo de

campo concentración, campo de fútbol, campo de golf, campo del honor, campo de refugiados, campo de tenis, mpo de tiro 
casa de acogida, casa de baños, casa de beneficencia, casa de campo, casa de citas (casa de camas, casa de compromisos, casa de mancebía, casa de tolerancia, casa de trato, casa de lenocinio, casa de prostitución, casa de putas), casa de comidas, casa de devoción, casa de Dios (casa de oración, casa casa del Señor), casa de dormir, casa de empeños (casa de préstamos), casa de expósitos, casa de fieras, casa de huéspedes. (casa de posada, casa de pupilos), casa de juego (casa de coima), casa de locos (casa de orates), casa de maternidad, casa de moneda, casa de recreo, casa de socorro, casa de té, casa de tía, casa de vacas, casa de vecindad

centro de convenciones, centro de día, centro de estética, centro de

centro hemodiálisis, centro de menores, centro de investigaciones, centro de recursos, centro de salud

cuarto cuarto de aseo, cuarto de banderas, cuarto de baño, cuarto de derrota, cuarto de estar, cuarto de estandartes

patio patio de butacas, patio de luces, patio de recreo

parque parque de artillería, parque de atracciones (parque de diversiones), parque de bomberos

pista pista de aterrizaje, pista de baile, pista de circo

plaza plaza de abastos, plaza de armas, plaza de toros

sala de actos, sala de audiencia, sala de conferencias, sala de descanso, sala

sala de espectáculos, sala de espera, sala de estudio, sala de exposiciones, sala de fiestas, sala de gobierno, sala de justicia, sala de partos, sala de lectura, sala de operaciones, sala de prensa, sala de vista

salón salón de actos, salón de belleza

taller taller de coches, taller de carpintería, taller de peletería, taller de relojero

zona zona de compras, zona de copas, zona de juegos, zona de obras

otras circuito de carreras, depósito de cadáveres, edificio de oficinas, gabinete de formas consultas, jardín de infancia, planta de reciclaje, torre de control

Fuente: Anuario de Lingüística Hispánica, XXV (2009)Universidad de Valladolid, Chenling LIU.

Según las características fundamentales de los compuestos que propone Bustos Gisbert (1986: 72-73), se comprueba que estos sustantivos locativos del tipo en $\mathrm{N}$ de $\mathrm{N}$ se identifican con los compuestos sintagmáticos. Puede examinarse esta relación desde tres perspectivas: 
a) Desde el punto de vista morfológico, estos sustantivos locativos manifiestan comportamientos como unidades de funcionamiento léxico: el género del compuesto se identifica con el del núcleo o determinado (el campo de bata-1la, el centro de recursos), se observa un mayor grado de fijación morfológica en los casos donde el núcleo o determinado recibe la determinación numérica (sala de visitas, casa de citas, centro de recursos, parque de atracciones, taller de reparaciones, circuito de carreras, salón de actos, banco de órganos, etc.) y no se acepta la presencia de diminutivos en el segundo elemento (*sala de visi-tita, *parque de bomberitos, *asa de citillas).

b) En el plano léxico, algunos de estos compuestos equivalen a una unidad léxica, como casa de beneficencia y hospital o asilo, casa de citas y prostíbulo, casa de expósitos e inclusa, casa de fieras y zoo(lógico), casa de locos y manicomio, depósito de cadáveres y morgue, sala de operaciones y quirófano, etc. Una característica que atañe al plano sintáctico se presenta en la modificación, pues solo es posible aquella complementación que afecta al compuesto en su totalidad: nuestra sala de visitas, gran campo de fútbol. No es esperable que estos compuestos admitan la coordinación del sintagma adnominal con otro de la misma naturaleza *sala de espera y de visita, *campo de fútbol y de balon-cesto.

c) Para la explicación semántica se aplican las nociones de endocentrismo y exocentrismo. En opinión de Bustos Gisbert (1986), los compuestos sintagmáticos endocéntricos difieren de los sintagmas nominales en el hecho de que no se refieren a "todo $\mathrm{X}$ (complejo) tal que $\mathrm{X}$ es B (núcleo) y posee la cualidad Y(complemento)", sino tan solo a alguna de las realidades que cumplen esta condición de ser B y poseer la cualidad. Así, una plaza de toros es una B (plaza) donde hay toros (Y), pero no cualquier plaza donde haya toros es una plaza de toros, sino tan solo aquella en la que se lidian. Por otro lado, en los nombres locativos exocéntricos del tipo $\mathrm{N}$ de $\mathrm{N}$, el primer elemento del grupo no puede considerarse propiamente como el núcleo referencial, pues no se interpreta en su acepción estricta sino más bien como equivalente del término genérico. Así, por ejemplo, en casa de socorro, casa representa al hiperónimo establecimiento, centro, etc., y no propiamente al término casa 'edificio para habitar, vivienda'. No obstante, la calificación del endocentrismo o exocentris-mo de los compuestos locativos no es absoluta, sino que existe una cierta grada-ción en el exocentrismo semántico. Tal gradación se deriva esencialmente de la modificación semántica del contenido del conjunto con respecto al contenido semántico del núcleo. Así, por ejemplo, en casa de citas se trata de un tipo de citas muy concreto, mientras que el segundo nombre de casa de fieras comporta el valor general referido a varias especies animales.

Así pues, la formación de nombres locativos en español se produce a partir de los dos procesos morfológicos principales: la derivación y composición, bien sea esta de tipo sintagmático o léxico.

\section{Conclusiones.}


- La formación de palabras locativas en español se produce a partir de los dos procesos principales, la derivación y la composición, que, a su vez, comprende la composición morfológica y la composición sintagmática. Cada uno de estos procesos incluye formaciones de distintas estructuras sintácticas y semánticas. En cambio, los sustantivos locativos del chino mandarín se forman mediante un único proceso, que consiste en la adición de formantes locativos pospuestos a determinadas unidades léxicas o palabras compuestas.

- Mediante el análisis contrastivo de estos nombres locativos en ambas lenguas, se observan algunas diferencias interesantes. Así, en español no parece darse un caso claro de gramaticalización semejante al de chăng 場 'explanada' en chino, pues mientras este formante locativo adquiere un carácter genérico local, los equivalentes en español se dispersan en compuestos morfológicos y formaciones derivadas. Además, la selección del núcleo nominal de la estructura $\mathrm{N}$ de $\mathrm{N}$ tampoco corresponde al significado de 'explanada, terreno llano'. No obstante, pueden observarse indicios de gramaticalización en otros nombres españoles que, sobre todo en sus orígenes, mostraron una alta productividad y una tendencia hacia el significado general de lugar. Tal vez, sería el ejemplo de casa el más próximo a este proceso de gramaticalización en formaciones del tipo casa de socorro, casa de fieras, casa de citas, casa de beneficencia, casa de campo, casa de huéspedes, casa de juego, casa de maternidad, etc.

- Por otra parte, al margen de los casos de formantes libres chinos como diàn 店 'tienda', yuàn 院 'edificio', guăn 館 'casa', zhàn 站 'parada', tái 台 'estrado', que alcanzan autonomía léxica en ciertos contextos, otros formantes como háng 行 'tienda', féng 坊 'tienda', pù 舖 'tienda', etc., se clasifican como afijos ligados que se corresponden funcionalmente con los elementos compositivos del español -teca, dromo, por presentar un origen culto y no admitir elementos afijales (yín háng 銀行 'plata' 'tienda' $\rightarrow$ banco; huā féng 花坊 'flor' 'tienda' $\rightarrow$ floristería; dàng pù 當舖 'empeñar' 'tienda' $\rightarrow$ casa de empeños).

- De ahí que aunque en su origen y clasificación ambas lenguas parecieran distar e incluso llegar a ser totalmente diferentes, en su esencia existen puntos de contactos que valdría la pena descubrir. Si se entiende la lengua como más que una forma de comunicación, buscar estas similitudes constituiría una forma de conectar almas.

\section{Referencias bibliográficas.}

ALMELA PÉREZ, Ramón, 1999. Procedimientos de formación de palabras en español. Barcelona: Ariel.

AMADOR RODRÍGUEZ, Alexis Luis, 2009. La derivación nominal en español: nombres de agente, instrumento, lugar y acción, Frankfurt am Main: Peter Lang.

BUSTOS GISBERT, Eugenio de, 1986. La composición nominal en español, Salamanca: Universi- dad de Salamanca. 
BUSTOS TOVAR, Eugenio de, 1966. "Algunas observaciones sobre las palabras compuestas", Revista Filología Española, XLIX, 255-274.

\section{CHANG LINLIU,2010. MORFOLOGÍA CONTRASTIVA DE LOS NOMBRES} LOCATIVOS EN CHINO MANDARÍN Y ESPAÑOL,Anuario de Lingüística Hispánica, XXV (2009), pp. 49-64,Universidad de Valladolid. ISSN 0213-053X

HOPPER, Paul. y TRAUGOTT, Elisabeth Closs, 1993. Gramaticalización, Cambridge: Cambridge University Press.

RAINER, Franz, 1993. Spanische Wortbildungslehre. Tubinga: Max Niemeyer.

RAINER, Franz, 2004. "Del nombre de agente al nombre de instrumento y de lugar en español: ¿cuándo y cómo?”, Iberoromania, 59, 97-122.

SANTIAGO LACUESTA, Ramón y Eugenio de BUSTOS GISBERT, 1999. "La derivación nominal", en Ignacio Bosque y Violeta Demonte (eds.), Gramática descriptiva de la lengua española, Madrid: Espasa Calpe, 4505-4594.

VAL ÁLVARO, José Francisco, 1999. "La composición”, en Ignacio Bosque y Violeta Demonte (eds.), Gramática descriptiva de la lengua española, Madrid: Espasa Calpe, Madrid: Espasa Calpe, 4757-4841.

VARELA ORTEGA, Soledad, 2005. Morfología léxica: La formación de palabras. Madrid, Gredos.

CAO, Bao.-Ping (曹保平), 2004. Hàn yǔ lèi cí zhuì yán jiù shù píng 漢語類詞緅研究述評 [Co- mentario del estudio de los pseudo-sufijos en la lengua china], Qu Jing Shi Fan Xue Yuan Xue Bao, 1: 69-72.

CHANG, Jia.- Hua. (張嘉驊), 1994. Xiàn dài hàn yǔ hòu zhuì jí qí gòu cí wèn tí zhī yán jiù 現代漢語後綴及其構詞問題之研究 [Estudio de los sufijos del chino moderno y sus problemas morfológicos], Tesis de Máster, National Chung Cheng University.

CHANG, Xiao.-Ping (張小平), 2003. “Dāng dài hàn yǔ lèi cí zhuì biàn xī 當代漢語類詞綴 辨析 [Análisis de los pseudo-sufijos del chino actual]”, en Ning-Xia Da Xue Xue Bao, 5: 22-25,65.

DONG, Xiu.-Fang (董秀芳), 2002. Cí huì huà: hàn yǔ shuāng yīn cí de yăn shēng hàn fā zhăn 詞彙化: 漢語雙音詞的衍生和發展 [Lexicalización: la derivación y el desarrollo de las palabras bisilábicas en la lengua china], Cheng Du: Si Chuan Ming $\mathrm{Zu}$. 
CHENLING LIULI, Charles N y A. THOMPSON SANDRA (2003 [1983]). Mandarin Chinese: A Functional Refe- rence Grammar [trad. HUANG, Xuan-Fan (黃宣範), 2003. Hàn yǔ yǔ fă 漢語語法 (Gra- mática china)], Taipei: Crane.

LÜ, Shu.-Xing (呂叔湘), 1992 [1942]. Lŭ shú xiāng wén jí: zhōng guó wén fã yào lüè 呂 叔湘文集：中國文法要略 [Acta de Lü, Shu-Xiang: plan de la gramática china], Taipei: $\quad$ Wen Shi Zhe.

PAN, Wen-Guo et al. (潘文國), 1993. Hàn yǔ de gòu cí fă yán jiù 漢語的構詞法研究 [Estudio sobre formación de palabras en la lengua china], Taipei: Tai Wan Xue Seng Shu Ju. 


\section{Para citar el artículo indexado}

Llanes Rosales, D. (2020). Contrastes morfológicos entre los nombres locativos del chino mandarín y el español. AlfaPublicaciones, 3(1), 66-78. https://doi.org/10.33262/ap.v3i1.40

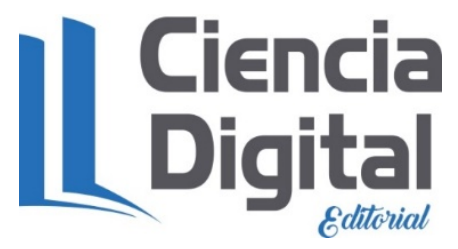

El artículo que se publica es de exclusiva responsabilidad de los autores y no necesariamente reflejan el pensamiento de la Revista Alpha Publicaciones.

El artículo queda en propiedad de la revista y, por tanto, su publicación parcial y/o total en otro medio tiene que ser autorizado por el director de la Revista Alpha Publicaciones.
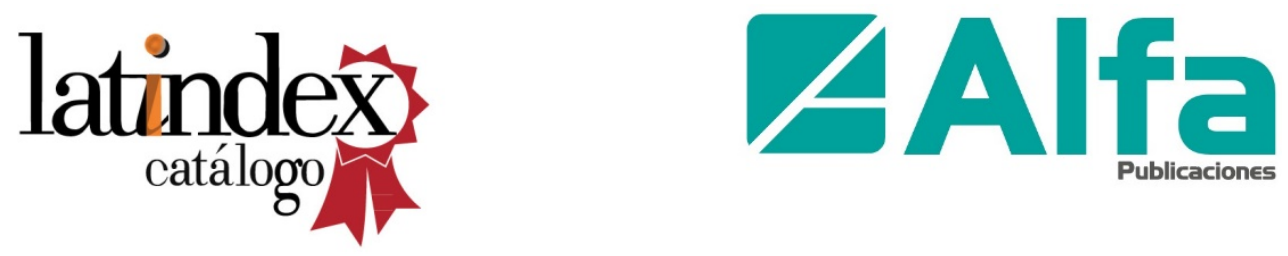